\title{
On the prediction of storm surges
}

\author{
P K DAS \\ A-59, Kailash Colony, New Delhi 110048 , India
}

\begin{abstract}
The article provides a review of some recent work on the prediction of storm surges. Beginning with a historical account of major Bay of Bengal cyclones in the last two decades, it provides a description of surge prediction techniques. The assumptions that are made are discussed critically. This is followed by an account of the forcing terms that drive the surge, and the computational procedure for model prediction. A brief comparison is presented between model outputs and the observed peak surge for major storms. Finally, the interactions of the surge with the astronomical tide, and wind-generated waves are discussed. Although the main focus of the article is on storms in the Bay of Bengal there is a brief description of cyclones in the Arabian Sea. The article ends with suggestions for improving surge prediction in the years to come.
\end{abstract}

Keywords. Storm surges; Bay of Bengal cyclones; surge prediction techniques.

\section{Introduction}

Storm surges belong to a genre of natural calamities that are classified as "windstorms". They are induced by strong winds driving a large mass of sea water towards the coast. This leads to a sudden inexorable rise in sea level much above the normal tidal elevation. It causes much damage to life and property. Table 1 provides a list of six major storms in the Bay of Bengal that have struck India and Bangladesh in the last two decades (1970 to 1990).

It is worthwhile to note the decline in the number of fatal casualties on the Indian coast over the years. This is due to improvements in warning services and a closer network of coastal radars. The Indian Space Programme has also helped to reduce casualties. Of considerable importance is a system of disseminating cyclone warnings on fast satellite telecommunication links from Madras. This is the only one of its kind in the Third World.

Cloud imageries from the INSAT (Indian National Satellite) series of geostationary satellites have provided valuable inputs on storm features. The important features that can now be monitored on near real-time are : (a) the location of the storm centre, (b) the radius of an inner ring of calm winds round the centre, and (c) an estimate of the pressure deficit between the storm centre and the outer atmosphere. Item (b) is not always possible unless the images are sharp, but on many occasions an 


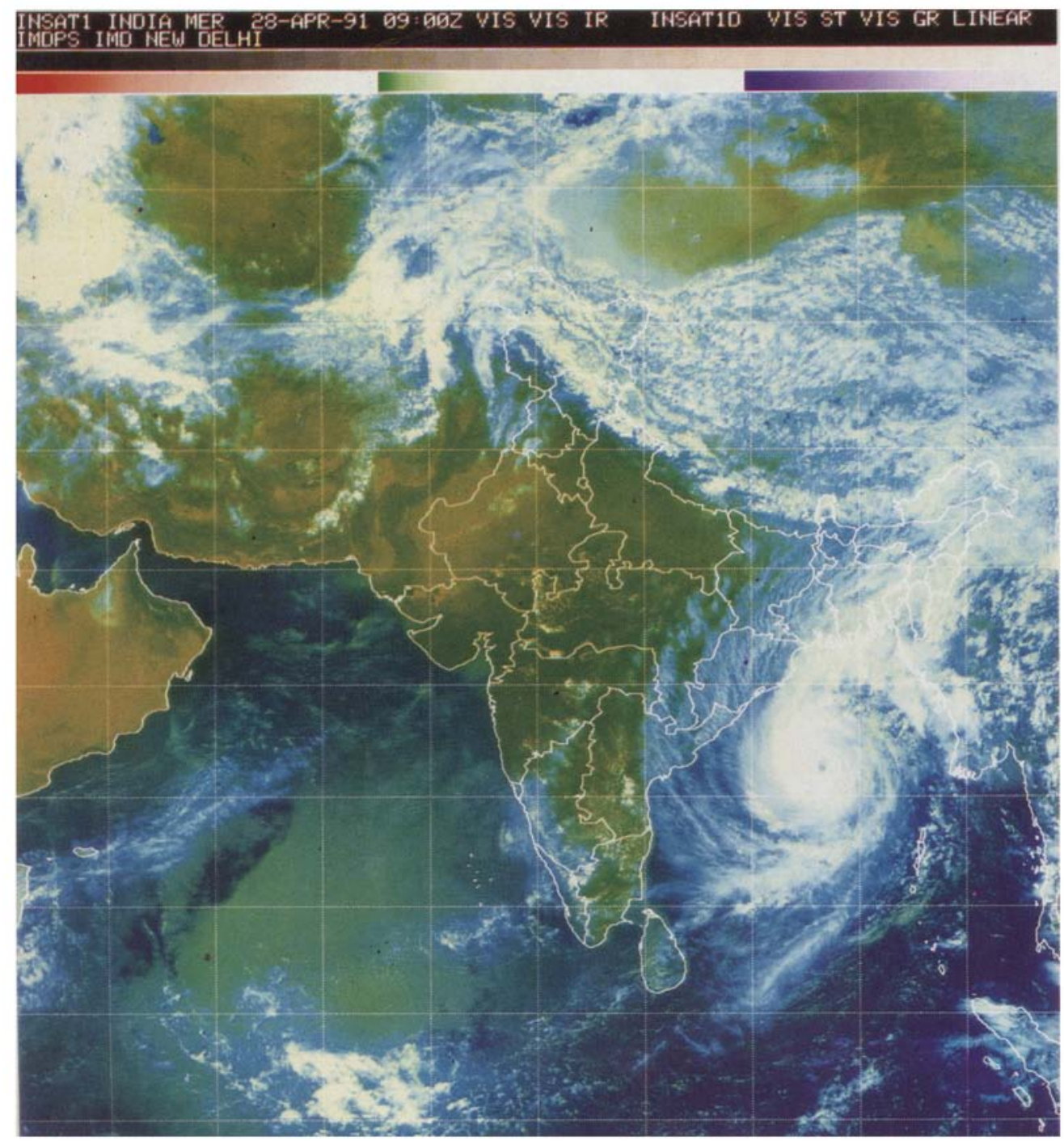

Satellite view of the Bangladesh cyclone of April 29/30,1993. The cyclone struck the Bangladesh coast between Hatia and Chittagong and calised 135,000 deaths. The sea level is reported to have risen by about $6 \mathrm{~m}$ above the mean. (Picture courtesy: India Meteorological Department.) 
Table 1. Major tropical cyclones (1970-1990).

\begin{tabular}{|c|c|c|c|}
\hline Year & Landfall & Country & $\begin{array}{l}\text { No. of deaths } \\
\text { (approx.) }\end{array}$ \\
\hline 1970 & Chittagong & Bangladesh & 300,000 \\
\hline 1971 & Paradip. Orissa & India & 10,000 \\
\hline 1977 & Chirala. Andhra Pradesh & India & 20,000 \\
\hline 1982 & Paradip. Orissa & India & 250 \\
\hline 1985 & Hatia & Bangladesh & 10,000 \\
\hline 1990 & Divi, Andhra Pradesh & India & 250 \\
\hline
\end{tabular}

approximate estimate is possible. Coastal radars also help to determine the radius of the eye.

Tropical cyclones are more frequent in the Bay of Bengal than in the Arabian Sea. The Bay cyclones, and their associated surges, are most frequent in the pre-monsoon months of April and May, and in the post-monsoon season from October to December. We will consequently focus on surges along the East Coast. The interested reader will find valuable information on storm surges, both in India and elsewhere, in a comprehensive review by Murty (1984).

\section{Early studies}

In early Indian work on surge prediction by empirical nomograms, Rao \& Mazumdar (1966) used a nomogram that was designed earlier by Sverdrup \& Munk (1947). A similar nomogram was used by Janardhan (1967) for estimating storm surges off Sagar Island at the northern end of the Bay of Bengal. Rao (1968) used the nomogram to delineate those sectors of the east and west coast of India which were vulnerable to dangerous surges. But, as these nomograms were based on empirical data the emphasis to-day is on predicting surges by numerical models.

Neumann \& Mandal (1978) used a statistical regression equation to predict the track of a cyclone. By using the past positions of a storm at 12-hour intervals as predictors they found a linear regression equation for the 72-hour displacement of a storm. Interestingly, they found that a linear combination of only 4 predictors explained $65 \%$ of the variance in the future position of the storm. This shows that a large number of predictors are not always necessary for good prediction.

Chaudhury (1978) adopted a different approach. He used the method of images generated by a complex potential due to a vortex of constant vorticity. The region was bounded by two orthogonal planes representing the Indian and Bangladesh coasts. The apex of this region was located at the head of the Bay of Bengal. Although the method was mathematically simple and attractive, a doubtful assumption was made, which was that the atmosphere was an ideal fluid with no viscosity.

Many tropical cyclones in the Bay of Bengal begin as remnants of low pressure systems off the South China Sea. They intensify into tropical cyclones on entering the Bay of Bengal. Some, however, continue to move westwards and, on crossing the southern tip of the Indian Peninsula, emerge into the Arabian Sea. They then intensify again into tropical cyclones. Here they recurve and move towards the Indian coast. The most vulnerable sectors of the West Coast are (a) a part of the Konkan coast 
north of $18^{\circ} \mathrm{N}$, and (b) a sector off the Rann of Kutch from Dwarka to Karachi in Pakistan.

\section{Surge models}

\subsection{Basic equations}

Surge prediction is built on the shallow water theory. This implies that the surge amplitude is small compared to the depth of the sea, which enables one to assume hydrostatic balance. The surge can thus be treated as a two-dimensional wave because the vertical component of motion is small in comparison with the horizontal components. A depth-averaged value of the current (V) is used in most conventional models but a few recent models are changing over to three dimensions. This provides a better representation of the vertical profile of $\mathbf{V}$.

The basic equations of a two-dimensional model are :

$$
\begin{aligned}
& \mathrm{DV} / \mathrm{D} t+f \mathbf{K} \times \mathbf{V}+g \nabla\left(\zeta+p_{a} / g\right)+(\alpha / H)\left(\tau^{s}-\tau^{B}\right)+A_{H} \nabla^{2} \mathbf{V}=0 \\
& \partial \zeta / \partial t+\nabla \cdot(H \mathbf{V})=0 \\
& \mathrm{D} / \mathrm{D} t \equiv \partial / \partial t+\mathbf{V} \cdot \nabla
\end{aligned}
$$

where

$$
\begin{array}{ll}
\mathbf{V} & =\text { the depth-averaged current vector, } \\
\zeta & =\text { sea-level elevation, } \\
h & =\text { depth of the sea bed }(Z=-h(x, y)), \\
H & =\text { total depth }(\zeta+h) \\
f & =\text { Coriolis parameter }(2 \Omega \sin \phi), \\
p_{a} & =\text { atmospheric pressure, } \\
\alpha & =\text { specific volume, } \\
\tau^{S}, \tau^{B} & =\text { frictional stress at the surface and on the sea floor respectively, } \\
A_{H} & =\text { coefficient of eddy viscosity, } \\
\nabla & =\text { two-dimensional del operator, }
\end{array}
$$

and $\mathbf{K}$ is the unit vector along the vertical axis of reference (figure 1).

By a scale analysis it is possible to show that the nonlinear terms in (1) and (2), and the effects of eddy viscosity, are small in comparison with the other terms as long as $Z / H \ll 1$, where $Z$ is a characteristic amplitude of the surge (Charnock \& Crease 1957); consequently, surge prediction models usually ignore nonlinear acceleration and eddy viscosity but the more recent models consider the complete equations.

\subsection{Forcing terms}

3.2a Atmospheric pressure: A pressure deficit of $1 \mathrm{mb}$ raises the sea level by $1 \mathrm{~cm}$. This follows from hydrostatic balance. This rise in sea level is referred to as an inverted barometer effect. If we know the difference in pressure between the centre of a storm and the outer atmosphere then the inverted barometer effect provides a first guess to the rise in sea level. But, as the surge is mainly generated by strong winds, the inverted barometer effect is small in comparison with the wind stress. As we will see shortly, the pressure gradients in the vicinity of a storm determine the winds that drive the surge. 


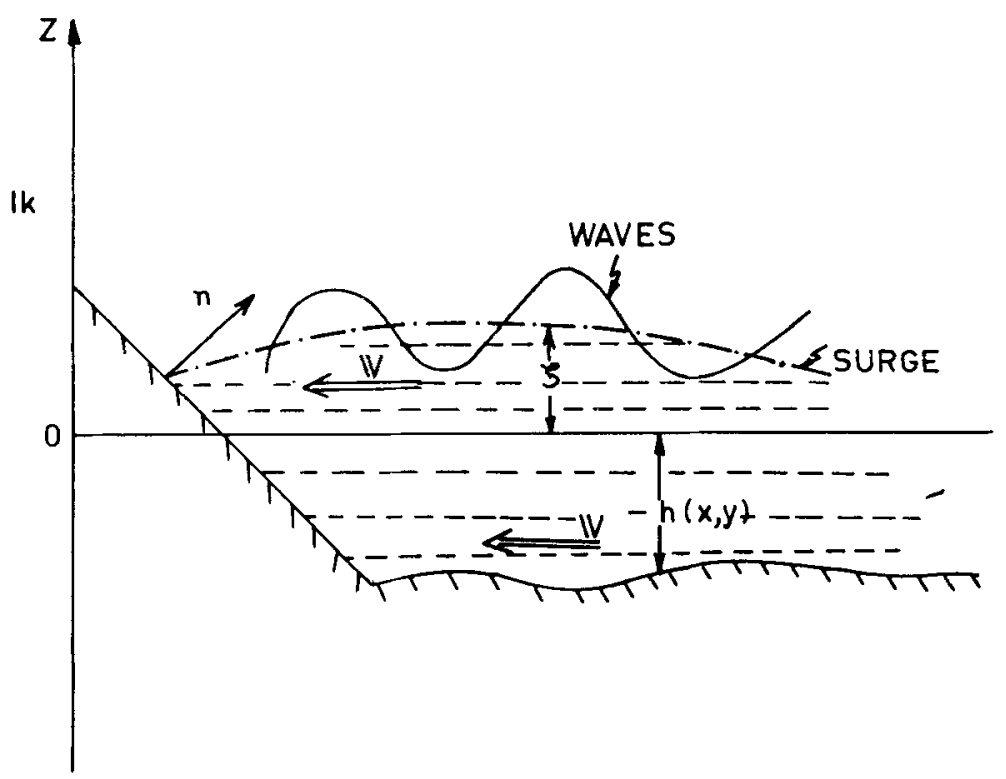

Figure 1. Schematic view of a surge.

$3.2 \mathrm{~b}$ The wind stress and the sea bed friction: The difference between the wind stress at the sea surface and the sea bed friction provides the main drive for the surge wave. The wind stress $\left(\tau^{s}\right)$ is related to the surface wind velocity $(U)$ at $10 \mathrm{~m}$ by

$$
\boldsymbol{\tau}^{S}=C_{\boldsymbol{S}} \boldsymbol{\rho}_{a} \mathbf{U}|\mathbf{U}|
$$

where $p_{a}$ stands for the density of air and $C_{S}$ is a surface drag coefficient. $C_{S}$ varies with the wind speed and the stability of the atmosphere. Most modellers use a constant value of $2.8 \times 10^{-3}$ for $C_{s}$, but empirical relations between $C_{s}$ and $U$ are also used.

The bottom stress $\left(\tau^{B}\right)$ is similarly related to the current vector $(\mathbf{V})$ by

$$
\tau^{B}=C_{B} \rho \mathbf{V}|\mathbf{V}|
$$

where $C_{b}$ is assigned a constant value of $2.5 \times 10^{-3}$.

Das (1972) assumed a steady Ekman spiral over the sea bed. For this current system

where

$$
\tau^{B}=\alpha \mathbf{V},
$$

$$
\alpha=0 \cdot 035 / h^{2} s^{-1} \text {. }
$$

The numerical constant $(0.035)$ in the numerator of $\alpha$ was determined empirically. The bottom stress is inversely proportional to the square of the depth.

There are uncertainties in this treatment. Ekman's spiral assumes a constant eddy stress coefficient, which is not realistic for the entire friction layer. Secondly, it is not clear whether the time taken to generate a boundary layer over the bottom of a shallow sea is comparable with the growth of the surge. In view of these uncertainties Flierl \& Robinson (1972) omitted sea bed friction in their model for the Bangladesh cyclone of 1970 . 
Johns et al (1983) used another innovative approach. They used a closure scheme based on a balance equation for the turbulent kinetic energy $(E)$. The generation of $E$ was balanced against (a) the rate at which $E$ is extracted from the mean flow, (b) the vertical transport of $E$, and (c) the dissipation of $E$ based on a similarity law. The scheme was used for a three-dimensional model of the Andhra Pradesh cyclone of 1977 (table 1). It was reported that there was not much difference in the final output between this scheme and the simpler equation (5). The determination of bottom stress remains one of the unsolved problems of surge prediction.

3.2c Storm structure and winds: The centre of a tropical cyclone is bounded by an inner ring of calm winds. This is the "eye" of the storm. The strongest winds are observed just beyond the eye-wall.

Earlier models used an idealised pressure profile to compute the associated winds. Thus, Das et al (1974) assumed the following profile

$$
p_{a}=1010-\Delta p /\left[1+(r / R)^{2}\right],
$$

where $\Delta p$ is the pressure deficit, $r$ is the radial distance from the storm centre and $R$ is the radius of the eye. Assuming a balance between the centrifugal force generated by rotating winds and the pressure gradient the following approximate expression was obtained for the maximum wind $\left(V_{m}\right)$.

$$
V_{m}^{2}=(13)^{2} \times \Delta p
$$

where $V_{m}$ is in knots and $\Delta p$ is in millibars. An advantage of this method is that $\Delta p$ can be estimated from real time satellite images of the storm. However, it assumes circular symmetry in the wind field.

Jelesnianski (1965) suggested another version. This is

$$
\begin{aligned}
& V=V_{m}(r / R)^{3 / 2} ; r \leqslant R, \\
& V=V_{m}(R / r)^{1 / 2} ; r>R .
\end{aligned}
$$

Yet another empirical relation by Johns \& Ali (1980) allows for a cut-off in wind strength beyond a distance $R_{1}$ from the centre. This is not easy to determine for real-time prediction.

A certain degree of asymmetry was introduced by Jelesnianski \& Taylor (1973) by the expression

$$
V=V_{m} \times 2 r R /\left(r^{2}+R^{2}\right) .
$$

This is valid for a stationary storm. A precise definition of the wind field round a cyclone is another area of uncertainty, but there are indications to suggest that improvements in satellite and radar technology will help us to overcome this difficulty in the future.

\section{Coordinate transformation and computational procedure}

A major difficulty in designing a model is to simulate an irregular coast. The coast is not a smooth mathematical curve which can be inserted in a model. Three different methods have been followed: 
(i) Staircase models: These models replace the coast by small horizontal and vertical segments in the form of a staircase (figure 2).

(ii) Continuous deformation: Staircase models sometimes fail to capture sharp changes in coastal curvature. To overcome this difficulty Johns et al (1983) introduced the following transformation,

where

$$
\xi=\left[x-b_{1}(y)\right] / b(y),
$$

whence

$$
b(y)=b_{2}(y)-b_{1}(y), \quad b_{1} \& b_{2} \text { are constants, }
$$

$$
\begin{aligned}
\xi & =0, & x=b_{1}(y) \\
& =1, & x=b_{2}(y) .
\end{aligned}
$$

The independent variables are now $\xi, y$ and time $(t)$ for a two-dimensional model. This transformation has been extensively used by Dube et al $(1981,1982)$ for surges in the Bay of Bengal.

(iii) Conformal transformation: Wanstrath (1976) introduced a conformal transformation to convert a curved domain into a rectangle. This avoids incorporating sharp changes in curvature. It has not been used much for the Indian coast, but a brief account has been reported by Mahadevan (1991).

At this stage it is difficult to assert which is best for the Indian coast because a detailed comparative study has not yet been made. Dube et al $(1981,1982)$ find that the staircase model tends to underestimate the peak surge by about $0.5 \mathrm{~m}$ in regions of rapid change in coastal curvature. This needs further study.

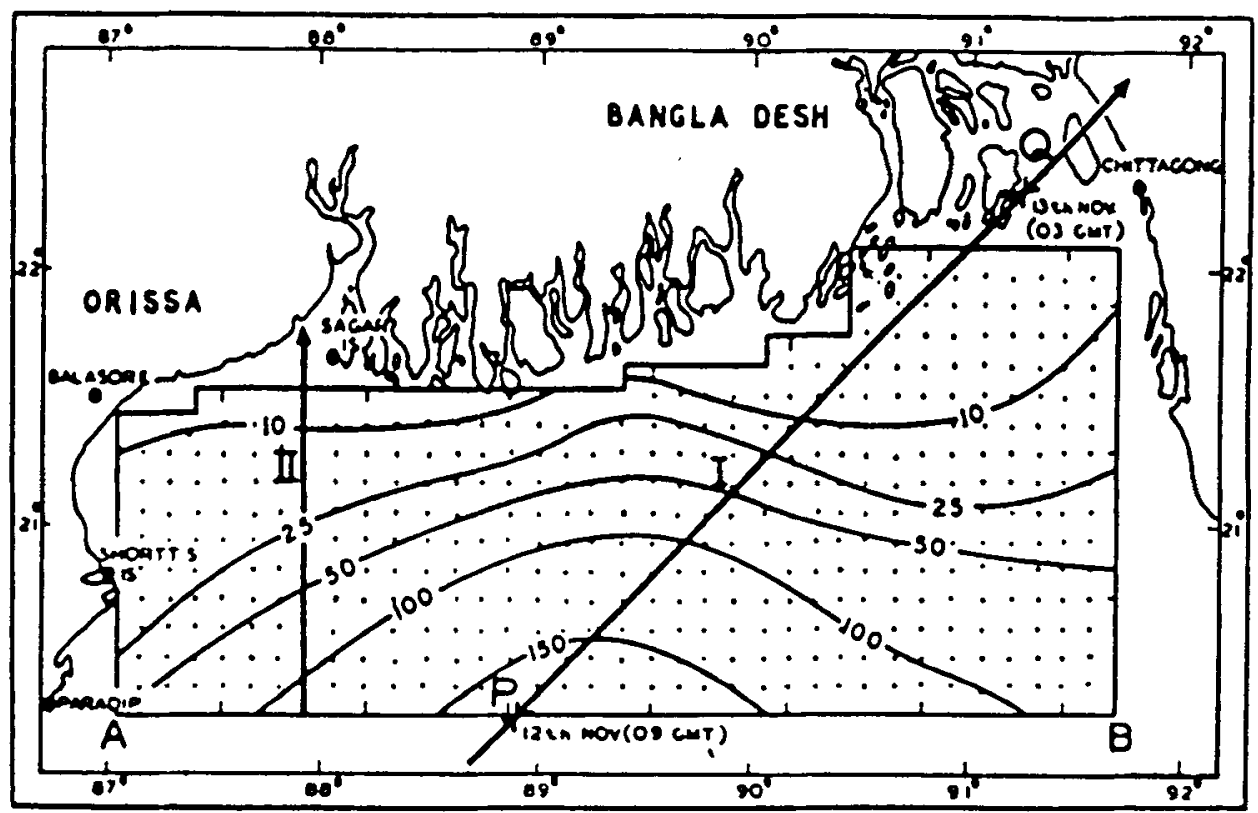

Figure 2. Grid for storms moving North-East (I) and North (II). Isopleths represent depth of the sea bed in metres (Das et al 1974). 


\subsection{Boundary conditions}

The region covered by a prediction model has a land boundary in the form of an irregular coast, and an open sea boundary away from the coast. Conventional models assume a vertical wall along the coast so that the lateral boundary condition makes the normal component of $\mathbf{V}$ vanish at the coast. We have

$$
\mathbf{n} \cdot \mathbf{V}=0
$$

where $\boldsymbol{n}$ is a unit vector normal to the coast. A more realistic boundary condition which considers a sloping coast is,

$$
\partial / \partial t(\zeta+h)+\mathbf{V} \cdot \nabla(\zeta+h)=0
$$

but this has not been tried yet because of inadequate data on coastal topography.

Along the open sea a radiation boundary condition is usually employed. This allows outward propagation of energy from the region under consideration, but inhibits inward energy flow. Heaps (1969) expressed this formally by

$$
v+(g / h)^{1 / 2} \zeta=0
$$

where $v$ is the meridional component of $\mathbf{V}$.

\subsection{Computational procedure}

The relevant equations are solved by considering their finite difference analogues. A staggered grid for the space variables and centred time differences are used. The grid is similar to Arakawa's (1966) energy conserving scheme, which conserves the kinetic energy in the region of interest, and prevents the growth of nonlinear instability. The stability criterion of Courant-Friedrichs-Levy (CFL) is used to determine the time steps. The criterion is,

$$
(g H)^{1 / 2} \Delta t / \Delta x<1,
$$

where $(g H)^{1 / 2}$ is the speed of gravity waves and $\Delta t, \Delta x$ are time and space increments. A nested grid, with higher resolution near the coast, was used by Das et al (1974). It provided better representation of the surge off the Orissa coast.

\section{Model verification}

The verification of model outputs is at present difficult because of an inadequate number of tide-gauges. On many occasions no tide-gauges exist near the landfall of a storm; consequently, the total sea level elevation is inferred from the tide-gauge nearest to landfall.

Interactions between the surge and the atmospheric tide are nonlinear. They could reduce the sea level elevation instead of raising it (Johns et al 1985).

In tables 2 and 3 we indicate the storm features, the tidal elevations and the observed maximum water level reported in different publications (Murty 1984; Dube 1992; Dube et al 1994). The results refer to the major storms mentioned earlier in table 1 . 
Table 2. Storm features.

\begin{tabular}{llccc}
\hline Date & \multicolumn{1}{c}{ Landfall } & $\begin{array}{c}\text { Central } \\
\text { pressure }(\mathrm{mb})\end{array}$ & $\begin{array}{c}\text { Pressure } \\
\text { deficit }\end{array}$ & $\begin{array}{c}\text { Maximum wind } \\
\text { speed }(\mathrm{km} / \mathrm{h})\end{array}$ \\
\hline 13 Nov 1970 & Chittagong, Bangladesh & 940 & 70 & 222 \\
30 Oct 1971 & Paradip, Orissa & 960 & 40 & 167 \\
19 Nov 1977 & Chirala, Andhra Pradesh & 909 & 101 & 250 \\
3/4 Jun 1982 & Paradip, Orissa & 950 & 50 & 216 \\
24 May 1985 & Hatia, Bangladesh & 975 & 21 & 120 \\
9 May 1990 & Divi, Andhra Pradesh & 920 & 80 & 230 \\
\hline
\end{tabular}

Table 3 shows reasonable agreement despite uncertainties, between the computed surge and the observed surge + tide, if we superpose the tide on the computed surge. But, the verification programme will improve if more tide gauge records were available.

Based on model outputs nomograms have been prepared by Das et al (1974) for the surge $(\zeta)$ as a function of the pressure deficit $(\Delta p)$ and the speed of the storm $(C)$. We have

$$
\zeta=a_{0} \Delta p+a_{1}(\Delta p)^{2}+a_{2} C
$$

where $a_{0}, a_{1}$ and $a_{2}$ are constants. The nomograms were prepared for storms that move (a) northeast towards Bangladesh, (b) northwards towards the Hooghly estuary, and (c) northwest to the Orissa coast. Numerical values of the constants are available in the original publication and will not be reproduced here, but a typical nomogram is shown in figure 3 . The nomograms are for pressure deficits less than $50 \mathrm{mb}$, but could be extended to higher values by (18), if required. A feature of the nomograms is a gradual approach to a constant surge amplitude for higher values of storm speed (C). This is to be expected because the faster storms provide less time for a response from the sea.

Similar nomograms were prepared by Jelesnianski (1974) for a generalised coastline. It is referred to as SPLASH (Special Programme for Listing Amplitudes of Surges from Hurricanes). Ghosh (1977) has applied this nomogram for the Bay of Bengal cyclones. SPLASH was later replaced by SLOSH, which stands for "Sea Level over Land Surges from Hurricanes".

Each nomogram has its own limitation because each assumes a hypothetical storm with a specified structure. Consequently, in recent years the trend is to compute the

Table 3. Computed peak surge and observed surge + tide.

\begin{tabular}{lccc}
\hline Date & $\begin{array}{c}\text { Computed peak } \\
\text { surge }(\mathrm{m})\end{array}$ & $\begin{array}{c}\text { Tide } \\
(\mathrm{m})\end{array}$ & $\begin{array}{c}\text { Observed } \\
\text { surge }+ \text { tide }(\mathrm{m})\end{array}$ \\
\hline 13 Nov 1970 & $4 \cdot 1$ & $1 \cdot 8$ & $6 \cdot 0-9 \cdot 0$ \\
30 Oct 1971 & $3 \cdot 5$ & $0 \cdot 9$ & $4 \cdot 0-5 \cdot 0$ \\
19 Nov 1977 & $5 \cdot 0$ & $0 \cdot 3$ & $5 \cdot 0-6 \cdot 0$ \\
3/4 June 1982 & $3 \cdot 5$ & $1 \cdot 3$ & $>3$ \\
24 May 1985 & $2 \cdot 0$ & $1 \cdot 7$ & $4 \cdot 5(*)$ \\
9 May 1990 & $4 \cdot 3$ & $0 \cdot 3$ & $4 \cdot 0-5 \cdot 0$ \\
\hline
\end{tabular}

(*) As reported by Bangladesh Meteorological Department 

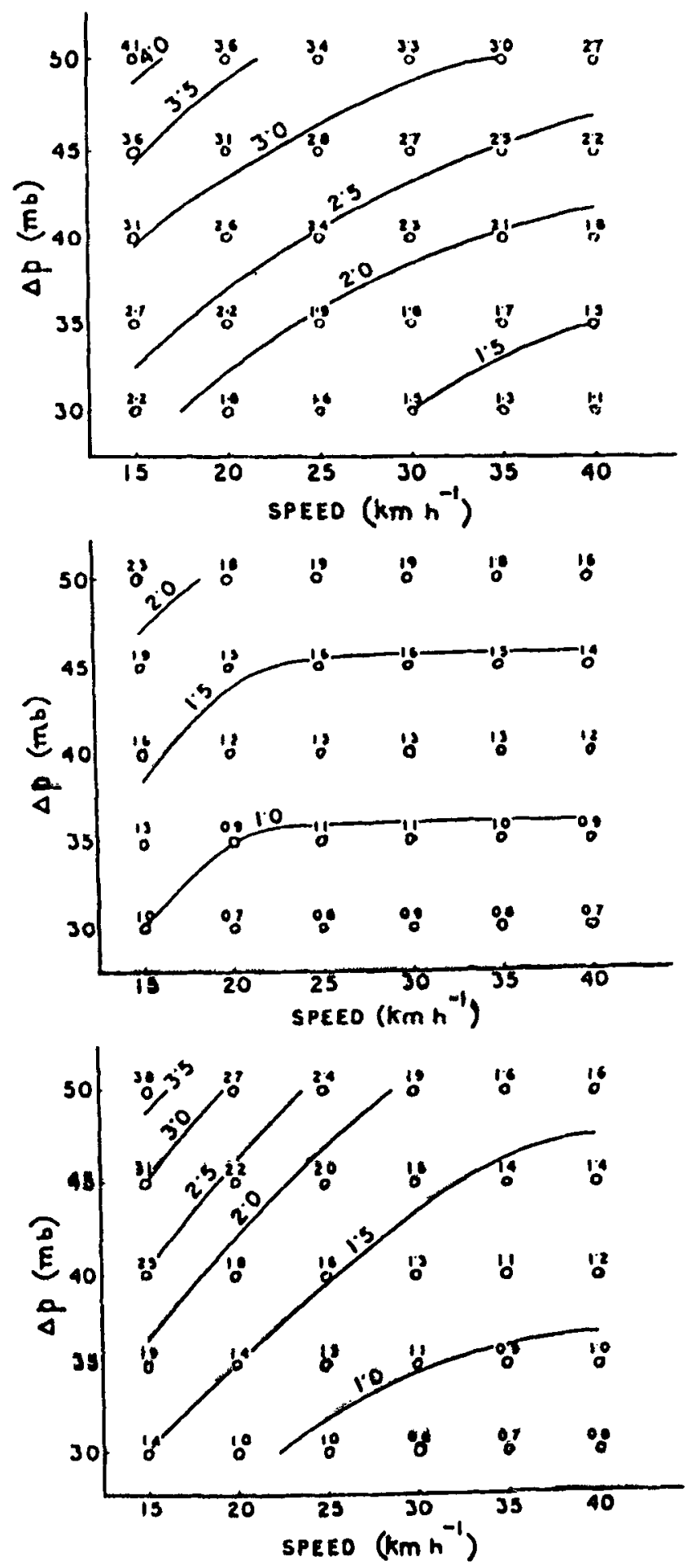

Figure 3. Nomograms from model generated storms: Sea level elevation $(\zeta, \mathrm{m})$, storm intensity $(\Delta p, \mathrm{mb})$ and speed $(C, \mathrm{~km} / \mathrm{h})$; North-East (I) (a), Northward (II) (b), and North-West (III) (c) tracks. (a) and (b) correspond to tracks (I) and (II) of figure 2 . 


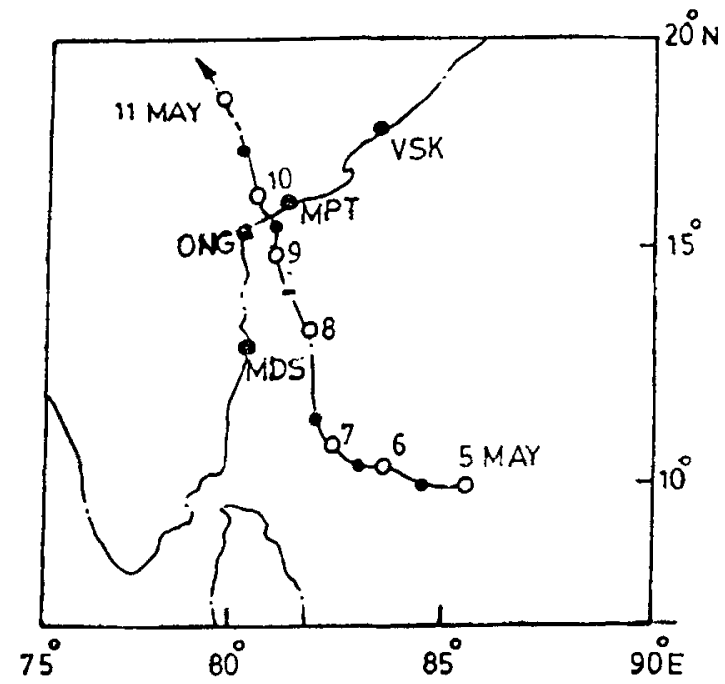

Figure 4. Path of the Andhra Pradesh cyclone of 1990 .

surge for each storm on a small computer located at a forecasting centre. A standard procedure and a programme for this has been worked out by Dube (1992). This will benefit real-time surge prediction in the country. The prediction of the 1990 Andhra cyclone is illustrated in figures 4 and 5 . This was done on a small computer.

\section{Future developments and summary}

There is considerable interest now in a coupled surge-tide-wave model. This is of much practical value because, as we can see, the total sea level elevation is the outcome of interactions between a surge, an astronomical tide and wind-driven waves. The period of the lunar semi-diurnal $\left(M_{2}\right)$ tide and the surge is of the same order $(5-12 \mathrm{~h})$. They are long gravity waves. But the period of a wind wave, which is a short gravity wave, is measured in seconds. We thus have a high frequency oscillation superposed on a low frequency oscillating system. There is little quantitative analysis of the interactions, or energy exchange, between these systems. The interactions will be most prominent in shallow water.

The other features which require further research are : (i) the Doppler shift in the frequency of waves on a current, (ii) an additional stress, known as the radiation stress, exerted by the waves on the surge, and (iii) the refraction of waves approaching a coast.

The principal conclusions may thus be summarised as follows.

(i) There is need for better data on sea level elevation near the landfall of a storm. This could be achieved by a closer network of tide gauges, and by observations of sea level from space.

(ii) Surge-prediction models may incorporate a sloping beach instead of assuming a vertical wall.

(iii) Better data on the wind profile associated with a storm could improve prediction.

(iv) Further research is needed for a more precise form of sea bed friction.

(v) A coupled surge-tide--wave model will provide better estimates of total sea-level elevation. 

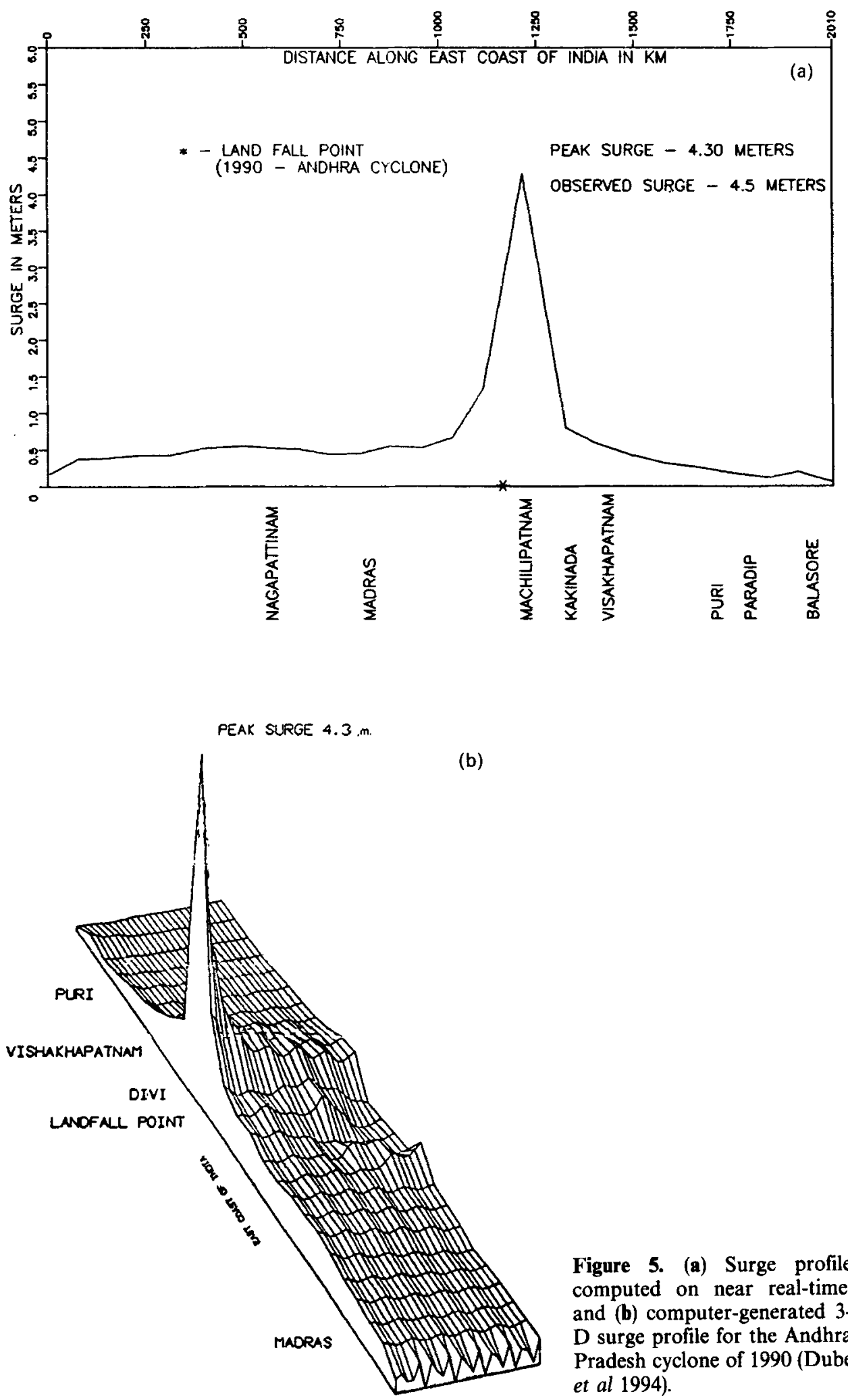

Figure 5. (a) Surge profile computed on near real-time, and (b) computer-generated 3D surge profile for the Andhra Pradesh cyclone of 1990 (Dube et al 1994). 
Dr G S Mandal of the India Meteorological Department kindly assisted me by providing information on recent cyclonic storms. I am indebted to him and Mr S D Gaur for their help.

\section{References}

Arakawa A 1966 Computational design for long-term numerical integration of the equations of atmospheric motion. J. Comput. Phys. 1: 119-143

Chaudhury A M 1978 Rose petals for tropical cyclones. Nucl. Sci. Appl. A2: 1-7

Charnock H, Crease J 1957 Recent advances in science: North Sea surges. Sci. Prog. 45: 494-511

Das P K 1972 A prediction model for storm surges in the Bay of Bengal. Nature (London) 239: $211-213$

Das P K, Sinha M C, Balasubramanyam V 1974 Storm surges in the Bay of Bengal. Q.J. R. Meteorol. Soc. (London) 100: 437-449

Dube S K 1992 Numerical modelling of storm surges in India and neighbourhood. Proc. ICSU/WMO Seminar on Tropical Cyclone Disasters, Beijing

Dube S K, Rao A D, Sinha P C, Chittibabu P 1994 A real-time storm surge prediction system: An application to the east coast of India. Proc. Indian Natl. Sci. Acad. A60: 157-170

Dube S K, Sinha P C, Rao A D 1981 The response of different wind stress forcings on the surge along the east coast India. Mausam 32: 315-320

Dube S K, Sinha P C, Rao A D 1982 The effect of coastal geometry on the peak surge. Mausam 33: $445-450$

Flierl G, Robinson A 1972 Deadly surges in the Bay of Bengal, dynamics and storm tide tables. Nature (London) 239: 213-215

Ghosh S K 1977 Prediction of storm surges on the east coast of India. Indian J. Meteorol., Hydrol. Geophys. 28: 157-168

Heaps N 1969 A two-dimensional numerical sea model. Philos. Trans. R. Soc. (London) A265: 93-137

Janardhan S 1967 Storm induced sea level changes at Saugor Island. Indian J. Meteorol. Geophys. 18: 205-212

Jelesnianski C P 1965 A numerical calculation of storm tides induced by a tropical storm impinging on a continental shelf. Mon. Weather Rev. 93: 343-358

Jelesnianski C P 1974 SPLASH NOAA Tech. Mem. NWS-TDL-52, NOAA, Washington DC

Jelesnianski C P, Taylor A D 1973 A preliminary view of storm surges before and after storm modification. NOAA Tech. Memo. ERL-WMPO.3, NOAA, Washington DC

Johns B, Ali A 1980 The numerical modelling of storm surges in the Bay of Bengal. Q. J. R. Meteorol. Soc. 106: $1-18$

Johns B, Rao A D, Dube S K, Sinha P C 1985 Numerical modelling of tide-surge interaction in the Bay of Bengal. Philos. Trans. R. Soc. (London) A313: 507-535

Johns B, Sinha P C, Dube S K, Mohanty U C, Rao A D 1983 Simulation of storm surges using a three-dimensional numerical model : an application to the 1977 Andhra Cyclone. Q.J.R. Meteorol. Soc. 109: 211-224

Mahadevan R 1991 Storm surges studies at Indian Institute of Technology, Madras - a review. Proc. Seminar on Mathematical Modelling of the Ocean (Bangalore: C-MMACs) p. 13a

Murty T S 1984 Storm surges, meteorological ocean tides (Ottawa: Dept. Fisheries and Oceans)

Neumann C J, Mandal G S 1978 Statistical prediction of storm motion over the Bay of Bengal and Arabian Sea. Indian J. Meteorol., Hydrol. Geophys. 29: 487-500

Rao N S B 1968 On some aspects of local and tropical storms in India. Ph D thesis, Univ. of Jadavpur

Rao N S B, Mazumdar S 1966 A technique for forecasting storm waves. Indian J. Meteorol. Geophys. 17: 333-346

Sverdrup H U, Munk W H 1947 Wind, sea and swell: Theory of relations for forecasting. H F publication no. 601, US Navy

Wanstrath J J 1976 Storm surge simulation in transformed coordinates, Vol. II: Program documentation. Tech. Rep. No. 76-3, US Army Corps of Engineers, VA 